\title{
Effects of cigarette tax on cigarette consumption and the Chinese economy
}

\section{T W Hu, Z Mao}

See end of article for

Tobacco Control 2002; 11:105-108

authors' affiliations

.................

Correspondence to:

Professor The-wei Hu, 412

Warren Hall, School of

Public Health, University of

California, Berkeley, CA

94720, USA

thu@uclink4.berkeley.edu

Received 26 March 2001

Accepted

12 October 2001
Objectives: To analyse a policy dilemma in China on public health versus the tobacco economy through additional cigarette tax.

Methods: Using published statistics from 1980 through 1997 to estimate the impact of tobacco production and consumption on government revenue and the entire economy. These estimates relied on the results of estimated price elasticities of the demand for cigarettes in China.

Results: Given the estimated price elasticities $(-0.54)$, by introducing an additional $10 \%$ increase in cigarette tax per pack (from the current $40 \%$ to $50 \%$ tax rate), the central government tax revenue would twice exceed total losses in industry revenue, tobacco farmers' income, and local tax revenue. In addition, between 1.44 and 2.16 million lives would be saved by this tax increase.

Conclusions: Additional taxation on cigarettes in China would be a desirable public policy for the Chinese government to consider.
C hina has a very high prevalence of cigarette smoking. According to a 1996 Chinese national survey, 63\% of adult males (age 15 years and over) and $3.8 \%$ of adult females were current smokers. ${ }^{1}$ These prevalence rates indicate that there are over 320 million cigarette smokers in China. ${ }^{1}$ Given the size of its smoking population, it comes as no surprise that China consumes more cigarettes than any other country in the world.

It is well known that cigarette smoking is a major health hazard. Many government officials in the Ministry of Health and public health professionals in China have recognised the importance of tobacco control; they have made a substantial effort to discourage cigarette consumption through a public health campaign. However, they have been unable to convince the Ministry of Finance, Ministry of Economics and Trade, or the Ministry of Agriculture to support tax increases as a means to control tobacco. Obviously, there is a policy conflict between public health concerns and the economic benefit of tobacco production. In China, tobacco production is a state run enterprise that provides substantial revenue for the government. Also, tobacco cultivation is a major income source for farmers in many poor regions. This conflict of interests among policymakers in public health and economics constitutes a major dilemma for the Chinese government.

In this paper we address this policy dilemma by describing and then analysing the economic consequences of a tax increase on cigarette consumption in the Chinese economy.

\section{CIGARETTE TAX AND GOVERNMENT REVENUE}

In China, the cigarette tax is considered a product tax that is levied on manufacturers or during importation. Cigarettes are valued (for tax purposes) at the producers level, not by the consumers. Value added tax is levied on retailers, since there is no sales tax collection system in China. This taxation practice, perhaps owing to the fact that cigarette production is a state run enterprise, is different from standard international practices, where tax rates are expressed as a percentage of the retail price. In China, the state enterprise is directly responsible for collection of the tax revenue when the product is shipped to market. The government levies two components of taxation on producers: the producers value added tax, which is about $17 \%$ of the producer price, and an additional approximate $50 \%$ of the wholesale price as consumption tax. Thus, from the producer's point of view, the tax paid to the government is $67 \%$ of the producer price. However, if the amount of tax paid by the producer is compared to the retail price of cigarettes, the effective tax rate is $38 \%{ }^{2}$

In 1997 China collected 90 billion Yuan in cigarette taxes and profit earned by the Chinese National Tobacco Company, about $11 \%$ of central government revenue. ${ }^{3}$ In short, cigarette tax revenue and profits are an important and reliable source of funds for the central government.

The importance of the role of cigarette taxes is further amplified by other factors: (1) local government levied tax on tobacco leaves, especially in those farming provinces (Yunan, Guizhou), is a major source of tax revenue; (2) both local and central government share cigarette tax from product tax; and (3) the China National Tobacco Company, which is a state enterprise, provides much value added profit as well as taxes to the central government.

Therefore, a recommendation to raise the cigarette tax rate would lead to a reduction in the demand for tobacco leaves and cigarette production, which is perceived by both the local and central governments as resulting in less government revenue. The subsequent section of this study will provide detailed analyses to show that the concern surrounding the issue of less tax revenue can be alleviated if additional tax is levied.

\section{PRICE ELASTICITY, CONSUMPTION, AND ITS IMPACT ON GOVERNMENT REVENUE}

To address the issue of the impact of tax on cigarette consumption and its subsequent impact on government revenue and tobacco leaf production, an analysis of the relation between price and consumption of cigarettes is required. This demand analysis is based on national aggregate time series data between 1980 through 1996.

Price elasticities are particularly important since they measure the effect of change in cigarette price on changes in cigarette consumption. Price elasticities are obtained statistically through the estimation of a demand function for cigarettes. A basic demand function usually includes the price of the cigarette, personal disposable income, and a time trend to reflect the change in consumer tastes and preferences. Several price elasticities have been estimated from Chinese 
provincial (Sichuan and Fujie) data, ranging from -0.40 to $-0.91 .^{4-6}$ This paper has used national aggregate per capita time series data from the Chinese statistical year book ${ }^{3}$ to estimate the price and income elasticities of the demand for cigarettes.

Two equations are used to provide these estimates: one without the lagged dependent variable (last period of cigarette consumption) which can provide an overall price elasticity, and one which includes the lagged dependent variable, which can provide both short run and long run price elasticity. The estimated demand equations are as follows:

$$
\begin{aligned}
& \ln \mathrm{Q}_{\mathrm{t}}=3.80-0.525 \mathrm{P}_{1}-0.002 \mathrm{I}_{1}+0.102 \mathrm{~T}_{1} \\
& \text { (6.323) (1.003) (13.172) } \\
& \overline{\mathrm{R}}^{2}=0.962 \quad \mathrm{DW}=2.17 \\
& \operatorname{LnQ}_{\mathrm{t}}=1.677-0.331 \mathrm{P}_{\mathrm{t}}+0.007 \mathrm{I}_{\mathrm{t}}+0.556 \ln \mathrm{Q}_{\mathrm{t}-1}+0.047 \mathrm{~T}_{\mathrm{t}} \quad \text { (Equation 2) } \\
& \begin{array}{ccc}
\overline{\mathrm{R}}^{2}=0.976 & (2.399) & (0.443) \\
& \mathrm{h}=1.25
\end{array} \\
& \text { (1.594) }
\end{aligned}
$$

where

$\ln \mathrm{Q}_{\mathrm{t}}=$ logarithm of annual aggregate cigarette sales in packs per capita, year t (1980-1996)

$\mathrm{P}_{\mathrm{t}}=$ cigarette price per pack (Yuan) in 1980 price, year $\mathrm{t}$

$\mathrm{I}_{\mathrm{t}}=$ income per capita (Yuan) in 1980 price, year $\mathrm{t}$

$\mathrm{T}_{\mathrm{t}}$ time trend from $1980=1, \ldots, 1996=17$

$\mathrm{R}^{2}=$ adjusted coefficient of determination with degrees of freedom

DW $=$ Durbin Watson statistics for testing autocorrelation

$\mathrm{h}=\mathrm{h}$ statistics for testing autocorrelation in lagged dependent variable equation.

Values in parentheses are t-values.

There is no autocorrelation in the first equation. The second equation has autocorrelation but is corrected by the CochranOrcutt method, with $\mathrm{h}$ statistics showing that there is no autocorrelation. Since these two equations are expressed in semi-log, the price elasticities can be calculated by the product of the price coefficient and the sample mean price of 1.03 Yuan, during the period 1980-1996. Thus, the overall price elasticity derived from equation 1 is -0.54 , while the short run price elasticity of -0.35 and -0.66 for long run price elasticity is derived from equation 2. All these estimated price elasticities are significant at the $1 \%$ level. These estimated national price elasticities are within the range of previous provincial estimates. With this estimated price elasticity one can address the issue of the impact of cigarette tax on cigarette consumption and government tax revenue.

To illustrate the possible impact of an increase in cigarette sales and additional resultant tax revenue, 1997 data on price and sales figures were used. The average nominal retail price per pack was 4.00 Yuan. ${ }^{3}$ For simplicity, we use Yuan as a currency benchmark. The sales of cigarettes were 33.67 million cases or 84.175 billion packs. The effective tax rate (expressed in retail price) is $38 \%$. For simplicity, we assume it is at $40 \%$, or 1.60 Yuan. If the Chinese government increases tax from 1.60 Yuan to 2.00 Yuan per pack, or a 25\% tax increase, the new retail price would be 4.4 Yuan/pack, a 10\% increase in retail price. Using the above estimated price elasticity, -0.54 , cigarette consumption can be reduced by $-5.4 \%$, the equivalent of 4.545 billion packs. The new cigarette consumption becomes 79.63 billion packs. Comparing the new tax revenue of 159.26 billion Yuan $(79.63 \times 2$ Yuan), and the previous tax revenue of 134.68 billion Yuan $(84.175 \times 1.60$ Yuan), the additional tax gain would be 24.58 billion Yuan. Similarly, if the price elasticity is set at -0.64 , cigarette consumption will be reduced by 5.387 billion packs, but the revenue will still increase by 22.89 billion Yuan. In summary, when the percentage decrease in quantity consumed is offset by the increase in prices (through the increase in tax), the increase in tax will lead to a reduction in cigarette consumption and an increase in tax revenue. In the long run, given the price elasticity is higher, -0.66 , than in the short run, -0.35 , it is expected that cigarette consumption will further decrease. This is a concern for the Chinese government. However, international experience shows that it will take time for smokers to adjust to the tax increase.

\section{STATUS OF CHINESE TOBACCO ECONOMY AND HEALTH COSTS}

To study the negative impact of tobacco tax on a tobacco economy, it is important to describe the status of the tobacco economy in both the agricultural and industrial sectors.

In 1997, China used 2.161 million hectares for tobacco growing ${ }^{3}$ and produced 39.08 million metric tons of tobacco leaves, with an average productivity of 1.81 metric tons per hectare. It has been estimated that about 5.6 million agricultural households are involved in tobacco production, ${ }^{7}$ although most of those households produce other agricultural crops as well. Their income does not rely entirely on tobacco. The tobacco leaf price was set by the government at an average of 3.962 Yuan per metric ton, or 242 Yuan per $50 \mathrm{~kg}$, in 1997. The total value of tobacco leaf production was 22.9 billion Yuan in 1997.

The tobacco manufacturing industry is a monopoly in China and is administered within the Ministry of Economics and Trade. China's tobacco industry produced 33.67 million cases (2500 packs per case) at a value of 129.6 billion Yuan. Cigarettes are a much value added product. The average profit of the cigarette manufacturing industry is $10.3 \%{ }^{8}$ of the total revenue. It has been estimated that it takes 0.041 metric tons of tobacco leaves to produce one case of cigarettes. ${ }^{9}$ The industry employs about 500000 people in the manufacturing sector and an additional 3.5 million are engaged in retail cigarette sales. ${ }^{10}$ However, only a few retailers are engaged solely in cigarette sales, as cigarettes represent only one commodity in the retail merchandise sector.

One negative aspect of cigarette smoking is its impact on healthcare costs. Cigarette smoking is harmful to one's health, causing premature death through smoking related illnesses such as lung cancer and cardiovascular disease. Smoking is also responsible for substantial healthcare costs and lost productivity as a result of illness and premature death.

A recent study by Jiang and Jin, ${ }^{11}$ using the 1998 mortality study of one million deaths in China, ${ }^{12}$ estimated that 514100 premature deaths occurred in 1998 from smoking related illness. Of these premature deaths, 210000 were caused by cancer, 190300 deaths involved the respiratory system, and 113700 involved the circulatory system. The number of person-years lost as a result of cigarette smoking was estimated at 1.146 million, using age 60 , the year of retirement in China, as a reference of productive age.

The study used 1998 national health services survey data to estimate the direct medical costs attributable to smoking. It was estimated that 347 million outpatient visits and 1.52 million inpatient admissions were attributable to smoking related illnesses. These services were valued at 17.1 billion Yuan for outpatient visits and 5.8 billion Yuan for inpatient services. Therefore, total direct medical costs attributable to smoking was 22.9 billion Yuan. As the overall total cost of medical services in China during 1998 was 377.6 billion Yuan, ${ }^{13}$ smoking accounted for $6 \%$ of China's healthcare expenditure.

\section{EFFECT OF CIGARETTE TAX ON THE ECONOMY}

An increase in cigarette taxes will reduce cigarette consumption. Therefore, it will have a negative effect on the cigarette industry and tobacco farmers. It is important to estimate these 
negative impacts so that government policymakers can be better informed when it comes to making decisions concerning cigarette tax.

When an additional tax is levied on cigarettes, the immediate impact is a reduction in sales, which will lead to a reduction in revenue as well as employment in the cigarette industry. Overall, the cigarette manufacturing industry employs about 500000 people. The value of cigarette production was 129.60 billion Yuan. $^{3}$

If we use the example of a $25 \%$ tax increase on a $40 \%$ tax base, as shown previously, the reduction in sales would be 4.545 billion packs (estimated at a price elasticity of -0.54 ). With a net price of 2.4 Yuan/pack (excluding tax, 4.4 Yuan -2 Yuan), the industry would lose revenue amounting to 10.91 billion Yuan. The average profit of the cigarette manufacturing industry is $10.3 \%^{8}$ of the total revenue. Thus, the loss of profit would be 1.12 billion Yuan.

If we consider employment to be a linear function of production volume, with a $5.4 \%$ loss of sales in the cigarette industry, employment rates would drop by the same percentage, which is about 27000 employees. This probably represents the maximum number of job losses, calculated at the average linear production relationship. In most cases, the attrition rate would be lower because of early retirement and job transfers. If one were to estimate the value of the loss of earnings from 27000 workers, assuming an annual income of 7200 Yuan, $^{3}$ the total loss of income would be 194.4 million Yuan.

The China Tobacco National Company is already in the process of eliminating inefficient factories and consolidating production. The increase in tax and reduction in cigarette consumption may provide further impetus to improve the efficiency of cigarette production. The effect of the reduction in cigarette consumption could lead the cigarette manufacturing industry to diversify into other products. Furthermore, the amount of money smokers save from cigarette consumption could also be spent on other food or household goods. Therefore, the net effect on employment could be smaller than estimated.

The Chinese tobacco farmers have been overproducing tobacco in recent years, according to the government purchase programme. ${ }^{9}$ In 1997, farmers produced 39.08 metric tons on 2.161 million hectares of land, with an average productivity of 1.81 metric tons per hectare. It takes 0.041 metric tons of tobacco leaves to produce one case of cigarettes (2500 packs). ${ }^{9}$ Thus, the reduction of 4.545 billion packs (or 1.82 million cases) as a result of the $25 \%$ tax increase would lead to a reduction in the demand for tobacco leaf by 0.0746 million metric tons. The average government purchase price for tobacco leaf was 484 Yuan per $100 \mathrm{~kg}$; thus tobacco farmers would lose 361.1 million Yuan. The average productivity per hectare was 1.808 metric tons; therefore, farmers could reduce the area of land they use to grow tobacco by 41261 hectares. This does not necessarily mean that this land would be left unfarmed. It could be used to grow other cash crops, such as tea or sunflowers. Although the return from these crops may not be as high as that from tobacco, by growing alternative crops the actual amount of revenue lost to tobacco farmers would be much less than the estimated 361.1 million Yuan.

The reduction in sales of tobacco leaves at the farm level implies a loss of local government tax revenue. As mentioned earlier, local governments encourage farmers to sell tobacco leaves in order to collect their local revenue. The local tax rate was 30\% before 1999 (20\% since 1999). Since tobacco farmers would lose 361.1 million Yuan, the local government could lose 108.3 million Yuan.

Considering the loss of revenue for the cigarette industry and income for tobacco farmers, the government may grant subsidies to the cigarette industry and tobacco farmers in order for them to transfer to other manufacturing industries as well as provide production opportunities. Needless to say,

\section{What this paper adds}

China has a very high prevalence of cigarette smoking, consuming more cigarettes than any other country in the world. However, tobacco production is a state run enterprise that provides substantial earnings for the government and is a major source of income for tobacco farmers in many poor regions.

This paper presents a quantitative economic analysis based on government statistics and price elasticities to show how to address the dilemma of public health issues versus economic imperatives. This paper simulates the net effect of a tobacco tax increase on the Chinese economy, showing it to be beneficial overall.

there are costs associated with this transition, as well as uncertainty over income and employment. Further studies or pilot experiments are required to examine these negative economic impacts on the tobacco industry and tobacco farmers.

HEALTH BENEFITS OF ADDITIONAL CIGARETTE TAX It has been estimated that the price elasticity of the demand for cigarettes can be divided into two parts: the elasticity of participation (or quitting), and the conditional elasticity of quantity demanded among smokers. The ratios vary from one third quit smoking to two thirds reduce consumption among smokers, or half the elasticity will reduce cigarette consumption. ${ }^{14}$

With a $25 \%$ tax rate increase ( 40 cents) at the 4 Yuan retail price (with a $40 \%$ tax base), a new retail price would increase by $10 \%$ to 4.40 Yuan. Using the price elasticity of -0.54 as an example, with 320 million smokers in China and a 10\% increase in price due to tax, $1.8 \%$ (5.76 million) to $2.7 \%$ ( 8.64 million) smokers in China would quit smoking. Using estimated epidemiological analysis reported by the World Bank, ${ }^{15}$ 1.44-2.16 million lives could be saved by a price increase of $10 \%$, or a tax increase of $25 \%$.

Recent work by Jiang and $\operatorname{Jin}^{11}$ estimated that the total direct medical cost attributable to smokers was 22.9 billion Yuan or 72 Yuan per smoker (22.9 billion/320 million smokers). With 5.76 million to 8.64 million smokers quitting, it implies that medical cost savings could be 415 million Yuan to 622 million Yuan.

A cigarette tax increase in China could therefore reduce cigarette consumption, generate more government tax revenue, save lives, reduce medical care costs, and increase productivity.

\section{CONCLUSIONS AND RECOMMENDATIONS}

Many countries around the world have taken the initiative to control cigarette consumption because of its impact on public health and healthcare costs. China is in a unique position because its relatively high smoking prevalence provides a large tax base; therefore, the imposition of a cigarette tax increase will have a significant effect in generating additional central government revenue and reducing cigarette consumption.

As an illustration of the impact of an increase in tobacco tax, a $25 \%$ tax increase would reduce cigarette consumption by 4.54 billion packs, resulting in additional tax revenue of 24.58 billion Yuan. Statistical analysis indicates that between 5.76 million to 8.64 million smokers would quit smoking, resulting in 1.44 million to 2.16 million lives saved. The savings of medical care costs would be 415 million to 672 million Yuan, not to mention the gains that would be made in productivity due to avoidance of premature death. These monetary benefits would offset the industry revenue loss of 10.91 billion Yuan (including a profit margin of 1.12 billion Yuan), the 27000 lost jobs (with a loss of 194.4 million Yuan in earnings) in the 
cigarette industry, the loss of tobacco income by 361.1 million Yuan (caused by a surplus of 0.0746 million metric tons of tobacco leaves), and the loss of local government revenue of 108.3 million Yuan. In essence, the overall monetary benefit far exceeds the negative impact on the cigarette industry and tobacco farmers. In financial terms alone, not counting the number of lives saved and medical care cost savings, the gain of the central government tax revenue ( 24.58 billion Yuan) twice exceeds the loss of tobacco farmers' earnings, tobacco industry workers' earnings, and loss of industry and local government revenue ( 11.74 billion Yuan.)

China is a major country in terms of tobacco consumption and production. Raising cigarette taxes for the government is both a public health issue and an economic issue. This paper has addressed both of these aspects. There is an issue concerning the impact of increased cigarette tax among different sectors of the economy and in the tobacco growing regions of the country. A short term solution could be cross subsidy from additional tobacco taxation to tobacco farmers and the cigarette manufacturing industry, which may result in transition to other products in the long term.

This paper is limited only to domestic cigarette production and consumption. Issues of cigarette smuggling in China and the pending impact of China's entry into the World Trade Organization (WTO) are not addressed. China's entry into the WTO has already led the government to consider further the implications of increased cigarette taxes on domestic and foreign cigarette production in the country. The findings of this paper have clearly indicated that increasing additional tax on cigarettes would be beneficial to the Chinese government from both the financial and public health perspective.

\section{ACKNOWLEDGEMENTS}

The World Bank and the Research for International Tobacco Control at the International Development Research Centre, Ottawa, Canada provided support of this study. The authors are grateful to three anonymous reviewers of this journal who provided most detailed suggestions. An earlier version of this paper was presented at the
11 th World Conference on Tobacco or Health in Chicago, 20 September 2000. The authors alone are responsible for the content of this paper.

Authors' affiliations

TW Hu, University of California at Berkeley, California, USA

Z Mao, Sichuan University, Chengdu, China

\section{REFERENCES}

1 Chinese Academy of Preventive Medicinel. Smoking and health in China: 1996 national prevalence survey of smoking patterns. Beijing: China Science and Technology Press, 1997.

2 Hu TW. Cigarette taxation in China: lessons from international experiences. Tobacco Control 1997:6:136-40.

3 China Statistics Bureau. China statistical yearbook. Beijing: China Statistical Publishing House, 1986-1998.

4 Mao ZZ, Jiang JL. Determinants of the demand for cigarettes, a cross-sectional study. Chinese Health Industry Management, 1997;227-9.

5 Mao ZZ, Jiang JL, Gong ZP. Demand for cigarette and pricing policy: a time-series analysis [in Chinese]. Chinese Health Economics, 1997:16:50-2.

6 Mao ZZ, Hsieh CR, Hu TW, et al. The demand for cigarettes in China Chengdu, Sichuan: West China Medical Sciences University, 2000

7 Nie H-P. How to deal with WTO-Issues of China tobacco leaf [in Chinese]. China Tobacco 2000;183(7):21-2.

8 Hong Kong City University. China markets yearbook, cigarettes. Hong Kong: Hong Kong City University, 1999:224.

9 Wang S, Li B. 1999-2000: analysis and estimate of the situation of China's tobacco sector [in Chinese and English]. Sino-World Tobacco 2000;47:6-11

10 Zhu J. How to coordinate the conflict between tobacco control and tobacco production in China. Periscope 1996;46:12-13.

11 Jiang $Y$, Jin S. Social economic burden attributed to smoking in China, 1998. Paper presented at the National Conference on Policy Development of Tobacco Control in China in the 21 st Century, Beijing, 29-31 May 2000.

12 Liu BO, Peto R, Chen ZM, et al. Emerging tobacco hazards in China: I. Retrospective proportional mortality study of one million deaths. BM 1998:317:1411-22.

13 Ministry of Health. Research on national health services-an analysis report of the national health service survey in 1993. Beijing: Ministry of Health, 1994:8

14 Warner KE, Chaloupka FJ, Cook PJ, et al. Criteria for determining an optimal cigarette tax: the economist's perspective. Tobacco Control $1995 \cdot 4: 380-6$

15 World Bank. Curbing the epidemic: government and the economics of tobacco control. Washington DC: World Bank, 1999:23.

\section{$\mathrm{ECHO}$}

\section{Smoking and mortality in 81344 drivers in Guangzhou, China T H Lam, C Q Jiang, S Y Ho, W S Zhang, W W Liu, J M He}

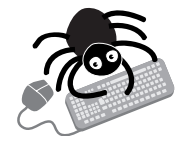

Please visit the Tobacco Control website for link to this full article-www. tobaccocontrol. com

Objectives: Previous studies on drivers focused on the effect of their exposure to vehicle exhaust and there is little evidence of the effect of smoking. This cohort analytical study aimed to examine the mortality of drivers relative to smoking and professional driving in Guangzhou, China.

Methods: Information on demographic characteristics, type of driver (professional and nonprofessional), smoking, and drinking were retrieved from medical records of drivers who applied for driving licences from March to December 1992. Vital status and causes of death of 81344 men aged 30 or above were ascertained to the end of September 1999 (follow up, mean $=7.14$ years, median $=7.17$ years). Results: At baseline, the mean (SD) age was 40.8 (5.6) years. One third were professional drivers; $49.0 \%$ were daily smokers. 858 Deaths were identified. The relative risk of overall mortality for ever smoking was 1.24 (95\% confidence interval (95\% CI) 1.07 to 1.44 ) after adjusting for age, alcohol drinking, education, and type of drivers. Compared with non-professional drivers, professional drivers had similar risks of death, and their relative risk of overall mortality for ever smoking was 1.35 (1.06 to 1.71).

Conclusions: Smoking is a more important cause of death than professional driving itself. The results show serious public health problems in the early stage of the tobacco epidemic and support urgent measures to help drivers stop smoking.

Occup Environ Med 2002;59:135-138 